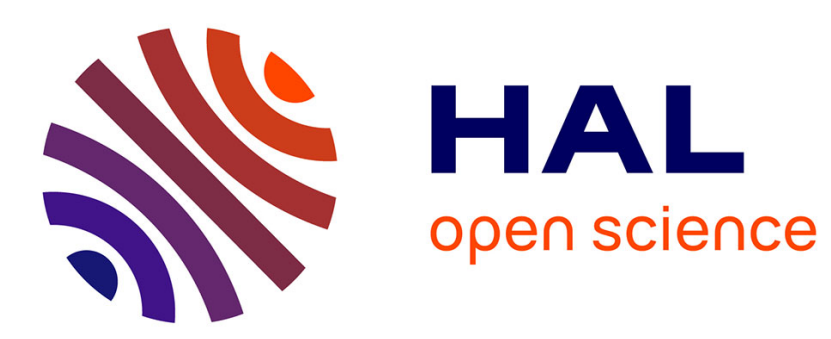

\title{
Self-Limited Grafting of Sub-Monolayers via Diels-Alder Reaction on Glassy Carbon Electrodes: An Electrochemical Insight
}

Walaa Nasser Al Dine, Ahmad Mehdi, Ibrahim Boumalham, Ziad Herro, André Vioux, Nicolas Brun, Olivier Fontaine

\section{To cite this version:}

Walaa Nasser Al Dine, Ahmad Mehdi, Ibrahim Boumalham, Ziad Herro, André Vioux, et al.. SelfLimited Grafting of Sub-Monolayers via Diels-Alder Reaction on Glassy Carbon Electrodes: An Electrochemical Insight. ACS Omega, 2019, 4 (24), pp.20540-20546. 10.1021/acsomega.9b02391 . hal-02418554

\section{HAL Id: hal-02418554 \\ https://hal.science/hal-02418554}

Submitted on 8 Dec 2020

HAL is a multi-disciplinary open access archive for the deposit and dissemination of scientific research documents, whether they are published or not. The documents may come from teaching and research institutions in France or abroad, or from public or private research centers.
L'archive ouverte pluridisciplinaire HAL, est destinée au dépôt et à la diffusion de documents scientifiques de niveau recherche, publiés ou non, émanant des établissements d'enseignement et de recherche français ou étrangers, des laboratoires publics ou privés. 


\title{
Self-Limited Grafting of Sub-Monolayers via Diels-Alder Reaction on Glassy Carbon Electrodes: An Electrochemical Insight
}

\author{
Walaa Nasser Al Dine, ${ }^{\dagger, \dagger}$ Ahmad Mehdi, ${ }^{\dagger} \oplus$ Ibrahim BouMalham, ${ }^{\S}$ Ziad Herro, ${ }^{\ddagger}$ André Vioux, ${ }^{\dagger}$ \\ Nicolas Brun, ${ }^{*}+\odot$ and Olivier Fontaine ${ }^{*}, \dagger, \|$ \\ ${ }^{\dagger}$ ICGM, Univ Montpellier, CNRS, ENSCM, Montpellier, France \\ ${ }^{\ddagger}$ Plateforme de Recherche en Nanoscience et Nanotechnologie, Faculté des Sciences 2, Université Libanaise, B.P 90656 Fanar, \\ Lebanon \\ ${ }^{\S}$ Laboratoire Energétique et Réactivité à l'Echelle Nanométrique (EREN), Faculté des Sciences IV, Université Libanaise, Haouch \\ el-Omara, 1801 Zahlé, Lebanon \\ "Réseau sur le Stockage Electrochimique de l'énergie (RS2E), FR CNRS, 80039 Amiens, France
}

\section{Supporting Information}

ABSTRACT: The grafting of molecular monolayers is critical for the functionalization of surfaces. In molecular electrochemistry, the surface modification of electrodes and the way molecules are attached to the electrode surface are highly critical to electron transfers and electrochemical reactions. In this paper, sub-monolayers were covalently grafted onto glassy carbon (GC) electrodes via Diels-Alder cycloaddition with two soluble dienophiles, that is, propargyl bromide and ethynyl ferrocene. Such an approach is clean (no by-product, no catalyst/additive) and occurs under mild conditions by

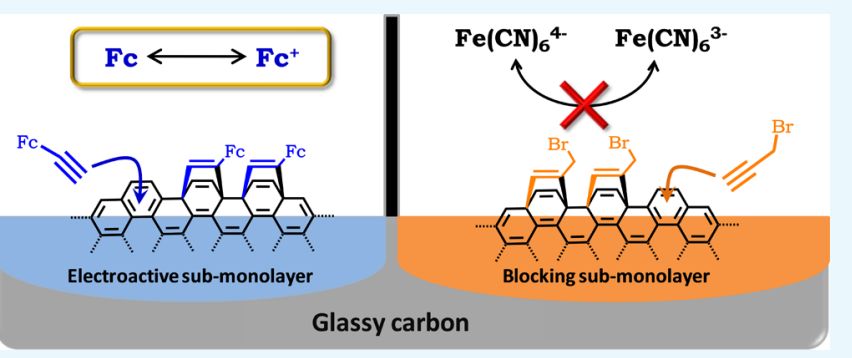
heating at $50{ }^{\circ} \mathrm{C}$ in toluene for few hours. The as-modified electrodes were thoroughly characterized by FTIR, XPS, and cyclic voltammetry using both millimetric GC electrodes and ultra-microelectrodes. Cyclic voltammetry gave access to surface coverage and clearly evidenced the covalent grafting of sub-monolayers. The grafting of functional sub-monolayers via DielsAlder cycloaddition could be easily extended to various functionalities and carbons to prepare electrochemical sensors or electrocatalytic surfaces.

\section{INTRODUCTION}

Surfaces are critical in a wide range of applications ${ }^{1}$ including catalysis, tribology, sensing, adsorption, corrosion, and electrochemistry as long as solid/gas or solid/liquid interfaces are involved. The fine control of both surfaces' composition and roughness has been a key lever to tune the physicochemical properties of both flat and porous substrates. In molecular electrochemistry, the surface modification of electrodes and the way molecules are attached to the electrode surface are highly critical to electron transfers and electrochemical reactions. ${ }^{2-4}$ Among substrates commonly employed in electrochemistry, gold and carbon-based electrodes ${ }^{5}$ have been the most popular and various grafting methods have been developed accordingly. As for carbon, the diversity of allotropes, for example, diamond, graphite, graphene, carbon nanotubes (CNTs), carbon black, and glassy carbons, and chemical purity led to various strategies to functionalize surfaces at the molecular level. Among $\mathrm{sp}^{2}$ hybridized carbons, which are of particular interest as long as electrical conductivity is required, the aryl diazonium salt approach ${ }^{6}$ has been widely used, particularly for the functionalization of $\mathrm{CNTs}^{7,8}$ and ordered mesoporous carbons. $^{9,10}$ The grafting of aryl diazonium salts can be performed through electrochemically induced reduction ${ }^{7,11}$ or spontaneous chemically/thermally induced reactions. ${ }^{8,9,12-14}$ Interestingly, Bahr and Tour ${ }^{8}$ first reported the in situ generation of diazonium salts and subsequent grafting on carbon nanotubes. As claimed by the authors, such an approach avoids the necessity of isolating and storing (often) unstable and light-sensitive aryl diazonium salts. Moreover, as compared with other methods developed for covalent functionalization of carbon materials, involving, beforehand, oxidation with nitric acid, oxygen, or ozone to generate oxygenated functionalities, ${ }^{15}$ the in situ generated diazonium salt approach is a single-step and straightforward process avoiding drastic damage usually caused by oxidative treatments.

Thus, the diazonium salt approach has offered a range of synthetic opportunities to functionalize carbon surfaces. As an example, Palacin et al. ${ }^{16,17}$ developed the so-called Graft fast process allowing the covalent grafting of polymer films via the chemical reduction of aryl diazonium salts and subsequent initiation of the radical polymerization of vinylic monomers.

Received: July 29, 2019

Accepted: November 14, 2019

Published: November 27, 2019 
Limoges et al. ${ }^{18}$ proposed to use the electrochemical reduction of phenylazide or phenylacetylene diazonium salts on glassy carbon electrodes as a versatile platform for click chemistry. On the one hand, these two elegant methods revealed, if still needed, the great versatility and potential of the diazonium salt approach. On the other hand, the reduction of diazonium salts usually leads to the formation of multilayered films, even though Toupin and Bélanger ${ }^{14}$ suggested a spontaneous selflimited monolayer grafting in the absence of electrochemical driving forces. Nevertheless, this so-called self-limited grafting seems to be more kinetic than thermodynamic. Another main drawback might rely on the use of additives, for example, sodium nitrite and sulfuric acid, especially for the in situ generation and/or chemically induced reduction of diazonium salts.

As an alternative two groups proposed, in 2004, the direct functionalization of single-walled CNTs via cycloaddition reactions. Langa et al. ${ }^{19}$ reported the Diels-Alder (DA) cycloaddition of $o$-quinodimethane under microwave irradiation, while Cosnier et al. ${ }^{20}$ grafted ferrocene through the 1,3dipolar cycloaddition of azomethyne ylides. More recently, Abetz et al. ${ }^{21}$ demonstrated the dual nature of the reactivity of carbon materials in DA cycloadditions. Depending on the nature of the soluble reactants, that is, furan or maleimide derivatives, CNTs could behave either as dienes or as dienophiles. Interestingly, this dual reactivity of carbon materials could offer a fine control over the surface chemistry, that is, self-limited monolayer versus polymeric film. Thus, consecutive DA cycloadditions of dienes, as dienophilic sites were autogenerated on the carbon surface while the DA reaction occurred, could be performed on carbon nanofibers. ${ }^{22}$ One may assume that such a multilayered polymerization is not possible when grafting soluble dienophiles on carbon surfaces.

Taking the "surface DA" functionalization one step further, Goettmann et al. ${ }^{23}$ extended this approach to various templated porous carbons acting as diene providers and soluble dienophiles such as propargylamine. In the same year, Urakami et al. ${ }^{24}$ took advantage of the polyfuran structure of biosourced hydrothermal carbons to graft various dienophiles such as maleimide. These two recent studies, together with the previous works, demonstrated clearly the versatility of this approach and implemented a powerful methodology to obtain functional porous carbon-based materials. Last but not the least, the DA cycloaddition reaction is advantageous as it does not generate any by-product, does not require any catalyst or additive, and can be performed under mild conditions and in solvent-free media. ${ }^{21}$

However, unlike the diazonium salt approach, the DA cycloaddition reaction has been sporadically reported for the covalent functionalization of carbon electrodes. Taking advantage of this rather simple approach, we propose herein the self-limited monolayer grafting of both non-electroactive and electroactive (i.e., ferrocene) alkyne derivatives onto glassy carbon electrodes. To the best of our knowledge, no thorough electrochemical study has ever been reported on monolayers grafted via DA cycloaddition. The aim of this work is to give an in-depth insight into such monolayers (or sub-monolayers) through the prism of electrochemistry.

\section{RESULTS AND DISCUSSION}

Grafting Method. As mentioned previously, the surface of $\mathrm{sp}^{2}$ hybridized carbons can act as diene providers, reacting potentially with soluble dienophiles such as alkyne groups via the Diels-Alder reaction (Scheme 1). Drawing our inspiration

Scheme 1. Suggested Reaction Scheme for the Functionalization of the Glassy Carbon Surface by Propargyl Groups with Dienes via Diels-Alder Reaction ${ }^{a}$
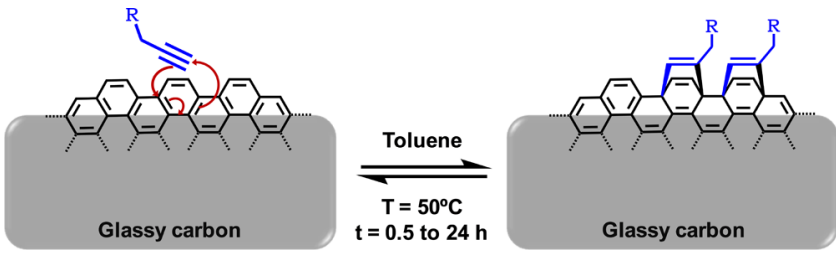

${ }^{a}$ In our case, $\mathrm{R}=\mathrm{Br}$ or ferrocene. The double arrow suggests that the retro-Diels-Alder reaction should be considered. However, no retroDiels-Alder reaction was observed at $50{ }^{\circ} \mathrm{C}$.

from Goettmann et al. ${ }^{23}$ and Urakami et al., ${ }^{24}$ we propose to extend this approach to glassy carbon electrodes using two soluble dienophiles: propargyl bromide and ethynyl ferrocene. While ethynyl ferrocene is electroactive and its covalent grafting can be directly followed through cyclic voltammetry, propargyl bromide is not and requires the use of a soluble redox probe, as it will be discussed later. The different electrodes prepared in this study are summarized in Table 1.

Table 1. Electrodes Studied Herein and the Associated Nomenclature

\begin{tabular}{lcc}
$\begin{array}{c}\text { grafted } \\
\text { dienophiles }\end{array}$ & $\begin{array}{c}\text { millimetric electrode } \\
\text { (macro) }\end{array}$ & $\begin{array}{c}\text { ultra-microelectrode } \\
\text { (UME) }\end{array}$ \\
none & Macro-bare & UME-bare \\
propargyl bromide & Macro-Br & UME-Br \\
ethynyl ferrocene & Macro-Fc & $\mathrm{X}$ \\
\hline
\end{tabular}

The DA cycloaddition reaction does not generate any byproduct, does not require any catalyst or additive, and can be performed under mild conditions. Herein, we proceeded at 50 ${ }^{\circ} \mathrm{C}$ immersing a glassy carbon electrode within $1 \times 10^{-2} \mathrm{M}$ solution of alkyne derivatives in toluene. Assuming that carbon surfaces are rather heterogeneous, one may suppose that both open and cyclic dienes are present and readily accessible to potentially react with the alkyne group. If the diene is already cyclic, which is most probably the case at the surface of glassy carbon electrodes (Scheme 1), the DA reaction will produce a bicyclic system. After the DA reaction took place, no diene remains (Scheme 1), avoiding any multilayered polymerization as usually observed via the diazonium approach. As a direct consequence, DA reactions should allow for a self-limited grafting of functional monolayers.

In order to evidence the effective surface modification of the electrodes, X-ray photoelectron spectroscopy (XPS) (Table S1 and Figure S1), contact angle measurements (Figure S2), Raman spectroscopy (Figure S3), and Fourier transform infrared spectroscopy (FTIR) were realized on millimetric glassy carbon substrates (Figure 1). As for XPS, about 0.05 at. $\% \mathrm{Br}$ and 0.33 at. \% Fe were detected for Macro-Br and MacroFc substrates, respectively (Table S1). The XPS Fe 2p spectrum obtained from Macro-Fc (Figure S1) displays two couples of intense peaks corresponding to divalent iron species (at binding energies of 708 and $721 \mathrm{eV}$ ) and to trivalent ones (at binding energies of 712 and $725 \mathrm{eV}$ ), as described previously in the literature for grafted ferrocene derivatives. ${ }^{25}$ 


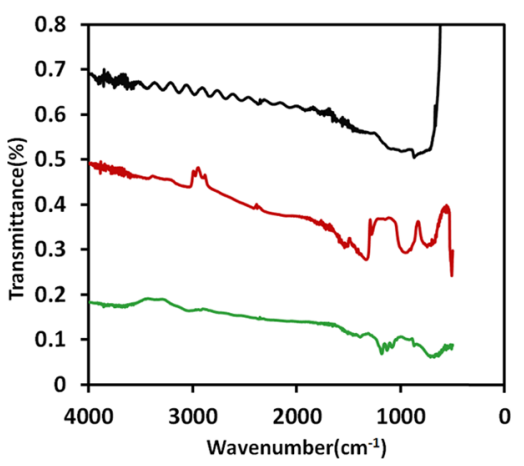

Figure 1. Fourier transformed infrared spectra obtained for Macrobare electrode (upper black curve), grafted propargyl $\mathrm{Br}$ electrode Macro-Br (lower green curve), and grafted ethynyl Fc electrode Macro-Fc (red curve, in the middle).

As XPS gives the relative chemical composition of surfaces at a depth of about $1-10 \mathrm{~nm}$, these values are clearly rather low, especially as we expect self-limited monolayers. XPS data can only be used to support the efficient surface modification of the electrodes but cannot be employed to quantify any surface coverage. This point will be discussed later via electrochemical methods. Contact angle measurements were also performed with water onto millimetric GC substrates as a qualitative way to demonstrate the efficient grafting of functional layers (Figure S2). Macro-bare and Macro-Br electrodes show similar wetting properties with contact angles in the range of $75-78^{\circ}$, slightly lower than graphite. ${ }^{26}$ After treatment with ethynyl ferrocene, a slight increase was noticed with a contact angle of about $88^{\circ}$, which could support the effective coverage of the
GC surface with hydrophobic ferrocene moieties. FTIR grazing angle measurement (Figure 1) and Raman spectroscopy (Figure S3) were also performed on Macro-bare, Macro-Br, and Macro-Fc glassy carbon substrates. On the one hand, Raman spectra highlight different features before and after grafting (Supporting Information). While both G and D bands (at 1580 and $1360 \mathrm{~cm}^{-1}$, respectively), typical of carbon materials, are clearly observed for the Macro-bare electrode, these bands are hidden by a strong fluorescence after DA cycloaddition (for both Macro-Br and Macro-Fc substrates). Even though the cause of such fluorescence is still subject to discussion, one may assume that the presence of freshly formed unsaturated bicyclic compounds onto the GC surface (Scheme 1) could be responsible for such a feature. On the other hand, grazing angle FTIR spectroscopy showed clear bands for both Macro-Br and Macro-Fc substrates (Figure 1). The bands associated with ferrocene groups are clearly identifiable in Figure 1 (red curve, in the middle): the band at $476 \mathrm{~cm}^{-1}$ corresponds to $\mathrm{Fe}-\mathrm{C}_{\mathrm{p}}$ stretching modes, while the ones centered at 1000 and $3014 \mathrm{~cm}^{-1}$ correspond to $\mathrm{sp}^{2} \mathrm{C}-\mathrm{H}$ inplane bending modes and stretching modes, respectively, and the band at $1407 \mathrm{~cm}^{-1}$ corresponds to $\mathrm{C}-\mathrm{C}$ stretching modes. The lower green curve in Figure 1 shows that we succeeded in grafting propargyl bromide groups. Apart from the band at $1078 \mathrm{~cm}^{-1}$ corresponding to $\mathrm{sp}^{2} \mathrm{C}-\mathrm{H}$ in-plane bending modes, a broad band corresponding to $\mathrm{C}-\mathrm{Br}$ stretching modes at $685 \mathrm{~cm}^{-1}$ can be observed.

Besides physicochemical characterizations, a thorough electrochemical study was conducted. Unlike ethynyl ferrocene, which is electroactive and can be directly followed through cyclic voltammetry, propargyl bromide is not and the
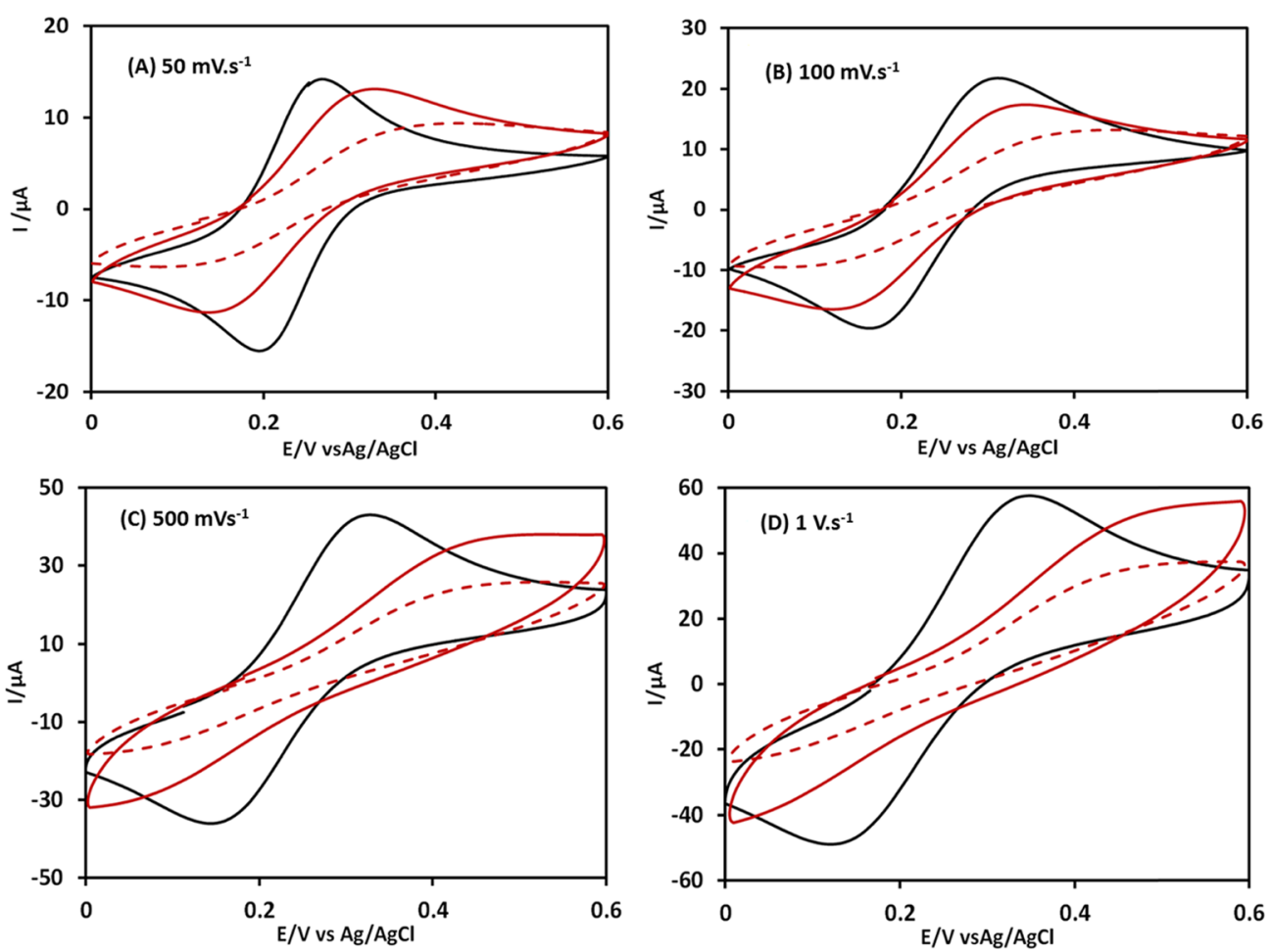

Figure 2. Cyclic voltammetry recorded at a $1.4 \mathrm{~mm}$ diameter glassy carbon millimetric electrodes in an aqueous electrolyte $(0.5 \mathrm{M} \mathrm{KCl})$ containing ferri/ferrocyanide $\left(2 \times 10^{-3} \mathrm{M}\right)$ and $\mathrm{Ag} / \mathrm{AgCl}$ as the reference electrode, at different scan rates of (A) 50, (B) $100,(\mathrm{C}) 500$, and (D) $1000 \mathrm{mV} \mathrm{s}$ and different surface conditions. Bare glassy carbon electrode (black), Macro-Br after $2 \mathrm{~h}$ of reaction (red), and Macro-Br after $24 \mathrm{~h}$ of reaction (dashed red). 
electrochemical study of its covalent grafting requires the use of a soluble redox probe, as it will be discussed later.

Grafting of Non-electroactive Molecules. Cyclic voltammetry was performed before and after different DA reaction durations $(0.5,2$, and $24 \mathrm{~h})$ as described earlier in the Experimental Section. Ferri/ferrocyanide was used in aqueous media (in $0.5 \mathrm{M} \mathrm{KCl}$ ) as a redox probe to evidence surface modification. Figure 2 presents cyclic voltammograms (CVs) recorded in ferri/ferrocyanide aqueous solution at four scan rates: $50,100,500$, and $1000 \mathrm{mV} \mathrm{s}^{-1}$. In each case, we recorded three voltammograms: one using a bare electrode (Macro-bare; black curve) and two others using Macro-Br electrodes (modified with propargyl bromide) after different reaction times, that is, $2 \mathrm{~h}$ (red curve) and $24 \mathrm{~h}$ (dashed red curve). For each scan rate, voltammograms recorded for the Macro-bare electrode clearly show two peaks corresponding to the oxidation and reduction of the electrochemical probe, that is, ferri/ferrocyanide. After $2 \mathrm{~h}$ of Diels-Alder grafting, the corresponding voltammograms display a decrease in the intensity of both peaks. While increasing the reaction time to $24 \mathrm{~h}$, both peaks nearly disappeared and the potential difference between the anodic and cathodic peaks $\left(\Delta E_{\mathrm{p}}\right)$ increased, indicating that the surface of the electrode is blocked. This feature is probably due to the efficient grafting of a monolayer of non-electroactive molecules, that is, propargyl bromide, which acts as a barrier to redox processes.

These results confirm the effective grafting of propargyl bromide molecules via the Diels-Alder reaction and suggest the formation of a close-packed insulating layer onto the glassy carbon electrodes. The quantification of surface coverage was investigated using the "partially blocked electrodes" model given by Amatore et al. in 1983. ${ }^{27}$ Two complementary calculations give an estimation of the surface coverage named $\theta$. The first one comes from the ratio of peak currents (eq 1), and the second one involves the ratio of apparent kinetic constants (eq 2).

$$
\begin{aligned}
& (1-\theta)=\frac{i_{\text {modif }}^{\mathrm{p}}}{i_{\text {bare }}^{\mathrm{p}}} \\
& k_{\text {app }}^{0}=k^{0}(1-\theta)
\end{aligned}
$$

where $i_{\text {modif }}^{\mathrm{p}}$ and $i_{\text {bare }}$ are peak currents for modified and bare electrodes, respectively, and $k_{\text {app }}^{0}$ and $k^{0}$ are kinetic constants for modified and bare electrodes, respectively, calculated using Nicholson and Chain's method. Using eqs 1 and 2, an estimation of the coverage is given and resumed in Table 2.

Table 2. Estimation of Coverage Depending on Two Electrochemical Methods, Using CVs at $50 \mathrm{mV} \mathrm{s}^{-1}$ for Peak Current and $1 \mathrm{~V} \mathrm{~s}^{-1}$ for Kinetic Constant

\begin{tabular}{ccc}
\hline time of incubation & $\theta$, using peak current & $\theta$, using kinetic constant \\
\hline $2 \mathrm{~h}$ & $6 \%$ & $60 \%$ \\
$24 \mathrm{~h}$ & $36 \%$ & $70 \%$ \\
\hline
\end{tabular}

In regard to the differences in surface coverage values obtained as a function of the equation used (Table 2), it is clear that mass and electron transports at modified interfaces are more complex than a simple linear diffusion. In fact, Amatore et al. $^{27}$ followed by many publications ${ }^{28-30}$ showed the combination of linear versus radial diffusion on partially blocked surfaces as a function of the scan rate. Thus, eq 1 is exact only if linear diffusion is considered. Beyond the accuracy of these surface coverage values, electrochemical estimations support the grafting of a sub-monolayer.

Our surface modification can be transposed to ultramicroelectrodes. Figure 3 shows cyclic voltammetry responses as a function of reaction times onto ultra-microelectrodes. The electrode passivation suggests the formation of insulating layers onto electrode surfaces.

As a partial conclusion, the proof of concept regarding the grafting of self-limited functional monolayers on glassy carbon electrodes by Diels-Alder reactions has been demonstrated. To further show the versatility of this approach, redox-active dienophile molecules, that is, ethynyl ferrocene, were also grafted on glassy carbon electrodes as mentioned earlier.

Grafting of Electroactive Molecules. The grafting of ethynyl ferrocene was performed employing the same experimental procedure as for propargyl bromide (see the Experimental Ssection). Cyclic voltammetry (Figure 4) was carried out before and after grafting at different Diels-Alder reaction times $(0.5,2$, and $24 \mathrm{~h})$. Unlike previously, no soluble redox probe was used to evidence electrode passivation. As ferrocene is a redox probe, electrochemistry allows demonstrating effective DA grafting through recording the electrochemical response of the grafted molecules themselves. Figure $4 \mathrm{~A}$ shows four cyclic voltammograms. The black curve corresponds to a bare electrode (Macro-bare). We can clearly see a capacitive shape without any redox peak. On the contrary, the three cyclic voltammograms recorded for MacroFc electrodes after $0.5,2$, and $24 \mathrm{~h}$ of DA grafting (blue, green, and red curves, respectively) show two redox peaks. Both green (after $0.5 \mathrm{~h}$ ) and blue curves (after $2 \mathrm{~h}$ ) are nearly superimposed with weakly intense peaks. After $24 \mathrm{~h}$ of DA grafting (Figure 4A; red curve), two well-defined and more intense peaks appear, corresponding to the oxido-reduction reactions of ferrocene. By increasing the scan rate, the current intensities of both oxidation and reduction peaks increase (Figure 4C). Both peaks clearly exhibit a Gaussian-like shape typical of a thin layer response. Drawing the current intensity of the oxidation peak as a function of the scan rate gave a quasi-linear trend line (Figure 4D), supporting the presence of a thin layer and no-diffusive effect of ferrocene (Figure 4D). The integral of the peak gives direct access to surface coverage of ferrocene using the Faradaic equation. The estimated surface density is of $2.4 \times 10^{-10} \mathrm{~mol} \mathrm{~cm}{ }^{-2}$ after $30 \mathrm{~min}$ of grafting, supporting the grafting of a sub-monolayer. After $24 \mathrm{~h}$ of reaction, the estimated surface density reaches the maximum surface density estimated for a monolayer of ferrocene, $\sim 4.5 \times$ $10^{-10} \mathrm{~mol} \mathrm{~cm}^{-2}$ assuming a hexagonal close packing. ${ }^{31,32}$ To make sure that the electrochemical response was due to purely DA covalent grafting, a blank experiment was performed using pure ferrocene instead of ethynyl ferrocene. The cyclic voltammograms obtained with the as-prepared electrode are shown in Figure 4B. Whatever the scan rate, no redox peak can be observed. This result clearly supports that the grafting of ferrocene occurred via DA reactions of ethynyl groups onto the carbon surface. In other ways, no physical adsorption was responsible for the characteristic electrochemical response of ferrocene, highlighting the efficiency of our approach.

\section{CONCLUSIONS}

Two alkyne derivatives were grafted onto the glassy carbon (GC) electrodes using the Diels-Alder (DA) cycloaddition reaction. The as-modified electrodes were thoroughly charac- 

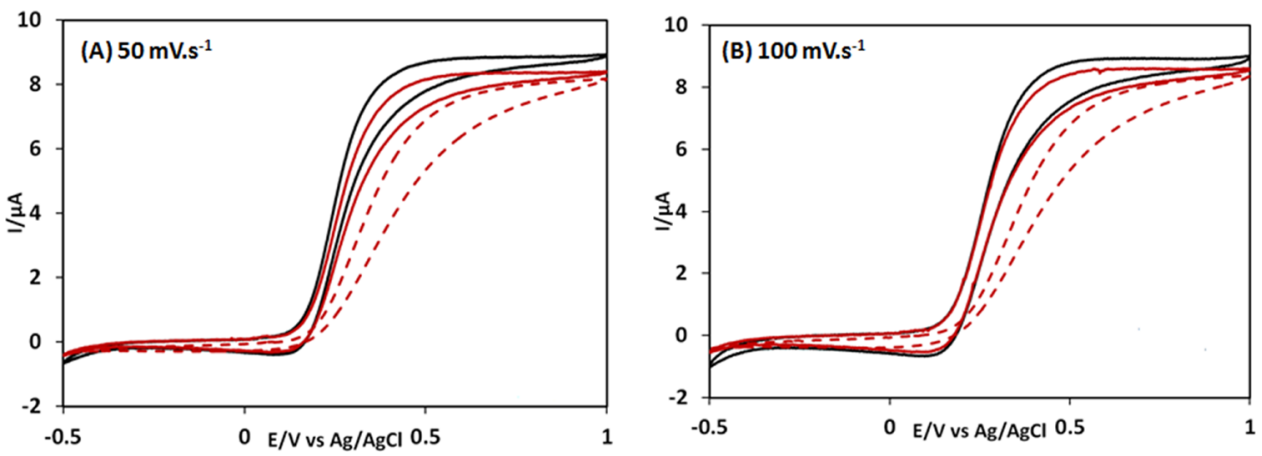

Figure 3. Cyclic voltammetry recorded at ultra-microelectrodes for ferrocyanide $\left(2 \times 10^{-3} \mathrm{M}\right)$ oxidation, in water containing $0.5 \mathrm{M} \mathrm{KCl}$ as the electrolyte and $\mathrm{Ag} / \mathrm{AgCl}$ as the reference electrode, at different scan rates of (A) 50 and (B) $100 \mathrm{mV} \mathrm{s}^{-1}$. Different electrodes were studied: bare glassy carbon electrode (black), Macro-Br after $2 \mathrm{~h}$ of reaction (red), and Macro-Br after $24 \mathrm{~h}$ of reaction (dashed red).
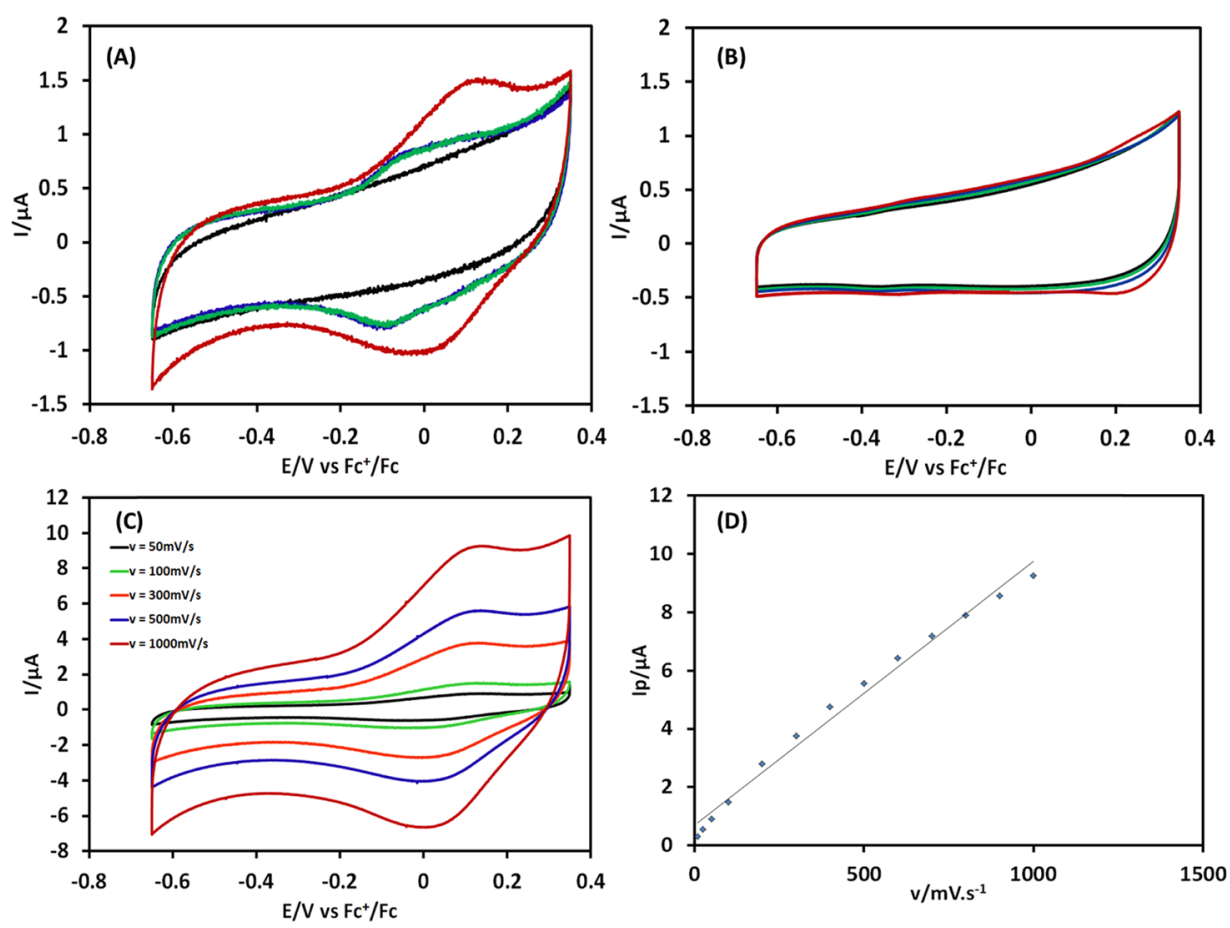

Figure 4. (A) Cyclic voltammetry on millimetric electrodes of ferrocene grafted onto the electrodes in $\mathrm{ACN}$ containing $0.5 \mathrm{M} \mathrm{LiClO}_{4}$ at different states of the surface. Bare glassy carbon electrode (black), Macro-Fc after $30 \mathrm{~min}$ of reaction (blue), Macro-Fc after $2 \mathrm{~h}$ of reaction (green), and Macro-Fc after $24 \mathrm{~h}$ of reaction (red). Scan rate: $100 \mathrm{mV} \mathrm{s}^{-1}$. (B) Cyclic voltammetry on the millimetric bare electrode, which is immersed in a solution containing ferrocene in toluene for $30 \mathrm{~min}, 2 \mathrm{~h}$, and $24 \mathrm{~h}$ before starting the CV. Scan rate: $100 \mathrm{mV} \mathrm{s}^{-1}$. (C) Cyclic voltammetry of ferrocene grafted after $24 \mathrm{~h}$ of reaction on the surface at different scan rates. (D) Values of the oxidation peak intensity for CV (C) as a function of scan rate values.

terized by spectroscopy techniques (XPS and FTIR), while cyclic voltammetry gave access to surface coverage and clearly evidenced the covalent grafting of molecular layers. Interestingly, we could give an in-depth insight into the as-generated sub-monolayers through the prism of electrochemistry. Both non-electroactive (i.e., propargyl bromide) and electroactive (i.e., ethynyl ferrocene) derivatives were successfully grafted, demonstrating the formation of either a close-packed insulating layer or a redox-active sub-monolayer.

Overall, we believe that this work further underpins the great potential of the DA cycloaddition reaction as a clean, powerful, and simple methodology to functionalize carbon electrodes. This reaction is advantageous as it does not generate any byproduct, does not require any catalyst or additive, and can be performed under mild conditions, that is, $50{ }^{\circ} \mathrm{C}$ in toluene for few hours. Finally yet importantly, such versatile methodology could be easily extended to various functionalities and substrates to prepare electrochemical sensors or electrocatalytic surfaces.

\section{EXPERIMENTAL SECTION}

Reagents. Propargyl bromide and ethynyl ferrocene were purchased from Aldrich. Most salts were ACS reagent grade, were purchased from Sigma-Aldrich, and used without further purification.

Surface Modification. Before modification, the glassy carbon electrodes were cleaned and mechanically polished with successively finer grades of alumina powder down to $0.05 \mu \mathrm{m}$. Surfaces were then sonicated in a water and acetone mixture to remove the polishing debris. Millimetric glassy carbon electrodes (3.0 $\mathrm{mm}$ diameter) or ultra-microelectrodes (10 
$\mu \mathrm{m}$ diameter) were immersed in $1 \times 10^{-2} \mathrm{~mol} \mathrm{~L}^{-1}$ propargyl bromide or ethynyl ferrocene in a toluene solution at $50{ }^{\circ} \mathrm{C}$ for $0.5,2$, or $24 \mathrm{~h}$. The as-modified electrodes were rinsed with toluene, dried, and rinsed with pure water before being immediately transferred into the electrochemical cell for cyclic voltammetry experiments.

Characterization. The samples were characterized by Xray photoelectron spectroscopy (XPS; ESCALAB 250 Thermo Electron) with a monochromatic excitation source ( $\mathrm{Al} \mathrm{K} \alpha$ ray; $1486.6 \mathrm{eV}$ ), Raman spectroscopy (Horiba Jobin Yvon LabRAM ARAMIS, $473 \mathrm{~nm}$ excitation), contact angle with water (Digidrop GBX, fast model/60), and Fourier transform infrared spectroscopy (Horiba Jobin Yvon - LabRAM ARAMIS, spectral ranges, 650 and $4000 \mathrm{~cm}^{-1}$ ). XPS, contact angle, and Raman spectroscopy data can be found in the Supporting Information.

Electrochemical Measurement. All the experiments were performed at room temperature. Electrochemical experiments were performed in aqueous solutions using water from a MilliQ purification system of a resistivity of $18 \mathrm{M} \Omega \mathrm{cm}$. Water was degassed for $20 \mathrm{~min}$ by bubbling argon prior to experiments. The electrochemical experiments were carried out with a threeelectrode glass cell. The working electrode was either a millimetric glassy carbon electrode $(3.0 \mathrm{~mm}$ diameter $)$ or an ultra-microelectrode (10 $\mu \mathrm{m}$ diameter). A Pt wire was used as the counter electrode, while a $\mathrm{Ag} / \mathrm{AgCl}$ electrode was employed as the reference. Cyclic voltammetry was performed with electrodes before and after grafting by the Diels-Alder reaction. Ferri/ferrocyanide $\mathrm{Fe}(\mathrm{CN})_{6}{ }^{3-} / \mathrm{Fe}(\mathrm{CN})_{6}{ }^{4-}$ at equal concentration of both forms, namely, $2.10^{-3} \mathrm{~mol} \mathrm{~L}^{-1}$ for each species, was used in aqueous media (in $0.5 \mathrm{M} \mathrm{KCl}$ ) as a redox probe to evidence the surface modification. Ohmic drop compensation was applied before each measurement.

\section{ASSOCIATED CONTENT}

\section{S Supporting Information}

The Supporting Information is available free of charge at https://pubs.acs.org/doi/10.1021/acsomega.9b02391.

XPS data, contact angle measurements, and Raman spectrum (PDF)

\section{AUTHOR INFORMATION}

\section{Corresponding Authors}

*E-mail: nicolas.brun@enscm.fr (N.B.).

*E-mail: olivier.fontaine@umontpellier.fr (O.F.).

\section{ORCID}

Ahmad Mehdi: 0000-0002-7830-2012

Nicolas Brun: 0000-0002-1013-311X

Notes

The authors declare no competing financial interest.

\section{ACKNOWLEDGMENTS}

O.F. thanks the French National Research Agency (STOREEX Labex Project ANR-10-LABX-76-01). The authors are grateful to reviewers for their valuable comments.

\section{REFERENCES}

(1) Somorjai, G. A.; Li, Y. Impact of surface chemistry. Proc. Natl. Acad. Sci. 2011, 108, 917-924.

(2) Alkire, R. C.; Kolb, D. M.; Lipkowski, J.; Ross, P. N. Electrochemical Surface Modification: Thin Films, Functionalization and Characterization. Wiley-VCH, 2008; Vol. 10, p 360.
(3) Bélanger, D.; Pinson, J. Electrografting: a powerful method for surface modification. Chem. Soc. Rev. 2011, 40, 3995-4048.

(4) Bard, A. J. Chemical Modification of Electrodes. J. Chem. Educ. 1983, 60, 302-304.

(5) Alkire, R. C.; Bartlett, P. N.; Lipkowski, J. Electrochemistry of Carbon Electrodes; Wiley-VCH Verlag GmbH \& Co. KGaA: Weinheim, Germany, 2015; p 450.

(6) Mahouche-Chergui, S.; Gam-Derouich, S.; Mangeney, C.; Chehimi, M. M. Aryl diazonium salts: a new class of coupling agents for bonding polymers, biomacromolecules and nanoparticles to surfaces. Chem. Soc. Rev. 2011, 40, 4143-4166.

(7) Bahr, J. L.; Yang, J.; Kosynkin, D. V.; Bronikowski, M. J.; Smalley, R. E.; Tour, J. M. Functionalization of carbon nanotubes by electrochemical reduction of aryl diazonium salts: A bucky paper electrode. J. Am. Chem. Soc. 2001, 123, 6536-6542.

(8) Bahr, J. L.; Tour, J. M. Highly functionalized carbon nanotubes using in situ generated diazonium compounds. Chem. Mater. 2001, 13, 3823.

(9) Li, Z.; Dai, S. Surface functionalization and pore size manipulation for carbons of ordered structure. Chem. Mater. 2005, 17, 1717-1721.

(10) Wang, X.; Liu, R.; Waje, M. M.; Chen, Z.; Yan, Y.; Bozhilov, K. N.; Feng, P. Sulfonated ordered mesoporous carbon as a stable and highly active protonic acid catalyst. Chem. Mater. 2007, 19, 23952397.

(11) Griveau, S.; Mercier, D.; Vautrin-Ul, C.; Chausse, A. Electrochemical grafting by reduction of 4-aminoethylbenzenediazonium salt: Application to the immobilization of (bio)molecules. Electrochem. Commun. 2007, 9, 2768-2773.

(12) Ellison, M. D.; Gasda, P. J. Functionalization of single-walled carbon nanotubes with 1,4-benzenediamine using a diazonium reaction. J. Phys. Chem. C 2008, 112, 738-740.

(13) Price, B. K.; Tour, J. M. Functionalization of single-walled carbon nanotubes "on water". J. Am. Chem. Soc. 2006, 128, 1289912904.

(14) Toupin, M.; Bélanger, D. Spontaneous functionalization of carbon black by reaction with 4-nitrophenyldiazonium cations. Langmuir 2008, 24, 1910-1917.

(15) Figueiredo, J. L. Functionalization of porous carbons for catalytic applications. J. Mater. Chem. A 2013, 1, 9351-9364.

(16) Mesnage, A.; Esnouf, S.; Jégou, P.; Deniau, G.; Palacin, S. Understanding the Redox-Induced Polymer Grafting Process: A Dual Surface-Solution Analysis. Chem. Mater. 2010, 22, 6229-6239.

(17) Mévellec, V.; Roussel, S.; Tessier, L.; Chancolon, J.; MayneL'Hermite, M.; Deniau, G.; Viel, P.; Palacin, S. Grafting polymers on surfaces: A new powerful and versatile diazonium salt-based one-step process in aqueous media. Chem. Mater. 2007, 19, 6323-6330.

(18) Evrard, D.; Lambert, F.; Policar, C.; Balland, V.; Limoges, B. Electrochemical Functionalization of Carbon Surfaces by Aromatic Azide or Alkyne Molecules: A Versatile Platform for Click Chemistry. Chem. - Eur. J. 2008, 14, 9286-9291.

(19) Delgado, J. L.; de la Cruz, P.; Langa, F.; Urbina, A.; Casado, J.; López Navarrete, J. T. Microwave-assisted sidewall functionalization of single-wall carbon nanotubes by Diels-Alder cycloaddition. Chem Commun. 2004, 1734-1735.

(20) Callegari, A.; Cosnier, S.; Marcaccio, M.; Paolucci, D.; Paolucci, F.; Georgakilas, V.; Tagmatarchis, N.; Vázquez, E.; Prato, M. Functionalised single wall carbon nanotubes/polypyrrole composites for the preparation of amperometric glucose biosensors. J. Mater. Chem. 2004, 14, 807-810.

(21) Munirasu, S.; Albuerne, J.; Boschetti-de-Fierro, A.; Abetz, V. Functionalization of Carbon Materials using the Diels-Alder Reaction. Macromol. Rapid Commun. 2010, 31, 574-579.

(22) Fernandes, F. M.; Araújo, R.; Proença, M. F.; Silva, C. J. R.; Paiva, M. C. Functionalization of Carbon Nanofibers by a Diels-Alder Addition Reaction. J. Nanosci. Nanotechnol. 2007, 7, 3514-3518.

(23) Kaper, H.; Grandjean, A.; Weidenthaler, C.; Schüth, F.; Goettmann, F. Surface Diels-Alder Reactions as an Effective Method 
to Synthesize Functional Carbon Materials. Chem. - Eur. J 2012, 18, 4099-4106.

(24) Urakami, H.; Antonietti, M.; Vilela, F. Facile functionalization of HTC-derived carbon microspheres. Chem. Commun. 2012, 48, 10984-10986.

(25) Tajimi, N.; Sano, H.; Murase, K.; Lee, K.-H.; Sugimura, H. Thermal Immobilization of Ferrocene Derivatives on (111) Surface of n-Type Silicon: Parallel between Vinylferrocene and Ferrocenecarboxaldehyde. Langmuir 2007, 23, 3193-3198.

(26) Taherian, F.; Marcon, V.; van der Vegt, N. F. A.; Leroy, F. What Is the Contact Angle of Water on Graphene? Langmuir 2013, 29, 1457-1465.

(27) Amatore, C.; Savéant, J. M.; Tessier, D. Charge Transfer at Partially Blocked Surfaces: A Model for the Case of Microscopic Active and Inactive Sites. J. Electroanal. Chem. 1983, 147, 39-51.

(28) Fontaine, O.; Laberty-Robert, C.; Sanchez, C. Sol-Gel Route to Zirconia-Pt-Nanoelectrode Arrays $8 \mathrm{~nm}$ in Radius: Their Geometrical Impact in Mass Transport. Langmuir 2012, 28, 3650-3657.

(29) Fontaine, O.; Trippé, G.; Fave, C.; Lacroix, J.-C.; Randriamahazaka, H. N. Microstructured electroactive surface based on binary self-assembled monolayer. J. Electroanal. Chem. 2009, 632, $1-7$.

(30) Lee, H. J.; Beriet, C.; Ferrigno, R.; Girault, H. H. Cyclic voltammetry at a regular microdisc electrode array. J. Electroanal. Chem. 2001, 502, 138-145.

(31) Leroux, Y. R.; Fei, H.; Noël, J.-M.; Roux, C.; Hapiot, P. Efficient Covalent Modification of a Carbon Surface: Use of a Silyl Protecting Group To Form an Active Monolayer. J. Am. Chem. Soc. 2010, 132, 14039-14041.

(32) Kongsfelt, M.; Vinther, J.; Malmos, K.; Ceccato, M.; Torbensen, K.; Knudsen, C. S.; Gothelf, K. V.; Pedersen, S. U.; Daasbjerg, K. Combining Aryltriazenes and Electrogenerated Acids To Create Well-Defined Aryl-Tethered Films and Patterns on Surfaces. J. Am. Chem. Soc. 2011, 133, 3788-3791. 